Article

\title{
Is Kazimierz Ajdukiewicz's Concept of a Real Definition Still Important?
}

\author{
Robert Kublikowski
}

The Department of Philosophy, The John Paul II Catholic University of Lublin, Al. Racławickie 14, 20-950 Lublin, Poland; robertk@kul.lublin.pl; Tel.: +48-604434515

Academic Editor: Urszula Wybraniec-Skardowska

Received: 20 March 2016; Accepted: 5 August 2016; Published: 17 August 2016

\begin{abstract}
The concept of a real definition worked out by Kazimierz Ajdukiewicz is still important in the theory of definition and can be developed by applying Hilary Putnam's theory of reference of natural kind terms and Karl Popper's fallibilism. On the one hand, the definiendum of a real definition refers to a natural kind of things and, on the other hand, the definiens of such a definition expresses actual, empirical, fallible knowledge which can be revised and changed.
\end{abstract}

Keywords: meaning; truth; ostensive definition; real definition; synthetic definition; analytic definition; revision

\section{Introduction}

We need knowledge of reality to act practically in a successful way. Such knowledge is expressed in statements (propositions), some of which take the form of a real definition. What is it? What is its function (role)? Is a real definition in fact important (useful)? "The old Socratic questions -What is Justice? What is courage? - call for definitions, not of words or concepts, but of things. To answer the question: 'What is courage?' in the intended sense is not to say what the English word 'courage' means, or what passes before the mind when we think of courage. It is to say what it is for a person to be courageous - to identify that in which the courage of the courageous person consists-by specifying non-trivial necessary and sufficient conditions for courage somehow grounded in the nature of courage itself" [1] (p. 189). The question "What is X?" demands an answer, which is a real definition.

Kazimierz Ajdukiewicz (1890-1963) — the Polish eminent philosopher, logician and a member of The Lvov-Warsaw School—was very interested in the methodological theory of definition, including a real definition.

Ajdukiewicz, as far as I know, did not work out the concept of an ostensive definition, which plays a fundamental, semantic (referential) role in the process of language acquisition. Moreover, he only mentioned the problem of the growth of a real definition. That is why my aim is to present, analyse and develop his concept of a real definition by applying, on the one hand, Hilary Putnam's theory of reference of natural kind terms and, on the other hand, by applying Karl Popper's fallibilism. I intend to show that Ajdukiewicz's ideas are still relevant to understanding what real definitions are and what their roles consist in. In this paper I am developing, in a critical way, ideas included in my book [2].

The paper consists of four main sections. First, I will analyse the problems concerning the reference of a definiendum of a real definition. A definiendum is a word being defined. Next, I will explain why a definiens of a real definition is revisable, fallible and changeable. A definiens expresses the meaning of a definiendum. Later, I will show that a real definition can be understood as a synthetic definition and also as an analytic definition. 


\section{A Relatively Stable Reference of Definiendum}

From a semantic and methodological point of view, the initial step in the process of defining an object is to perceive it. The next step is to point it out and to name it, i.e., to give it "a linguistic label", which becomes a definiendum. In this way the used name begins to designate an object-the reference (extension) of a given name is fixed. Pointing an object out and naming it is a method (procedure) which results in an ostensive definition. "There are two obvious ways of telling someone what one means by a natural-kind term such as 'water' or 'tiger' or 'lemon'. One can give him a so-called ostensive definition -'this (liquid) is water'; 'this (animal) is a tiger'; 'this (fruit) is a lemon'; where the parentheses are meant to indicate that the 'markers' liquid, animal, fruit, may be either explicit or implicit. Or one can give him a description. In the latter case the description one gives typically consists of one or more markers together with a stereotype [...] —a standardized description of features of the kind that are typical, or 'normal'" [3] (pp. 229-230).

In order to learn more about an ostensive definition and a description of natural kind terms, let us analyse the following situation: Mary Leakey, a paleoanthropologist and archaeologist, discovered a part of a skull at Olduvai Gorge in Tanzania (Africa) in 1959. She grasped that it belonged to a species yet unknown at that time. So she pointed that object out and said: "This is a part of a skull of the new species Zinjanthropus boisei".

Zinjanthropus boisei (the name changed to Australopithecus boisei and later Paranthropus boisei) is an early human fossil about 1.8 million years old and is described as follows: the wide zygomatic arches project forward of the nasal opening and form the dished-shape face. The outward flaring of these bony arches from the side of the head provided space for large temporalis muscles. These were the huge chewing muscles that passed from the lower jaw to the large sagittal crest atop the skull. In some cases, the megadont cheek teeth were four times the size of our own [4].

As it has already been said, the paleoanthropologist pointed the object out and named it. Yet, the question arises: what is pointing out when someone is using an ostensive definition-an element of an object, a composition of elements, a shape, a size, a colour of an object or a whole object, etc.?

A name refers to an object pointed out by a finger. The object is the first one which crosses the straight line fixed by the finger [5] (p. 163). However, it is still not clear how "deep" this pointing out is. Did the paleoanthropologist point out the surface of a particular object or the depth of it (a "deep structure")? In such a situation the intention of the paleoanthropologist is a crucial, pragmatic element of the process of defining. She wanted to point out the object as the sample of the newly discovered species. Putnam explained this issue analysing the example of water: "it has long been our intention that a liquid should count as 'water' only if it has the same composition as the paradigm examples of water (or as the majority of them). I claim that this was our intention even before we knew the ultimate composition of water. If I am right then, given those referential intentions, it was always impossible for a liquid other than $\mathrm{H}_{2} \mathrm{O}$ to be water, even if it took empirical investigation to find it out" [6] (pp. 220-221).

However, the problem is what justifies treating a part of a skull as an example of the newly discovered species? Moreover, the paleoanthropologist treated the pointed object as a typical, representative, normal sample of the same new species. How could she know that the sample was a representative one and not an abnormal one? Does it mean that such a sample has to have a particular quality or perhaps a set of essential (important) qualities, such as a chemical structure, etc.? "Importance is an interest-relative notion. Normally the 'important' properties of a liquid or solid, etc., are the ones that are structurally important: the ones that specify what the liquid or solid, etc., is ultimately made out of-elementary particles, or hydrogen and oxygen, or earth, air, fire, water, or whatever-and how they are arranged or combined to produce the superficial characteristics" [3] (p. 239).

The situation of giving a name (definiendum) to an object is the starting point of the linguistic chain established between the first usage of a term and its next usages. Each usage is causally connected. Namely "linguistic competence is a matter of knowledge plus causal connection to introducing events (and ultimately to members of the natural kind itself). [...] the use of a natural kind word involves in 
many cases membership in a 'collective' which has contact with the natural kind, which knows of tests for membership in the natural kind, etc. only as a collective" [3] (p. 205).

Moreover, the following user is linguistically obliged to use the term in a correct way. It means that a competent user has to know an "official" description (a stereotype) of a class of objects. For example, "it is obligatory to acquire the information that stereotypical tigers are striped if one acquires 'tiger"' [3] (p. 251).

The meaning of a definienum is fixed in an empirical way by pointing out the reference of the definiendum, and in this way the definiendum of a real definition obtains a relatively stable reference. Namely "the intention to preserve reference through a historical chain of uses and the intention to cooperate socially in the fixing of reference make it possible to use terms successfully to refer" [6] (p. 17).

As stated before, a real definition consists of a definiendum and a definiens. The question is whether the empirically established meaning (reference) of the definiendum is just "delivered" to the definiens (description) and thereby the definiens obtains its meaning? Or maybe this process goes in a different way? I will try to answer this question in the following sections.

A real definition, which characterises a set of objects (a species), has been called a real definition per genus et differentiam specificam [7] (pp. 81-82), [8]. A definiendum of such a real definition refers to (denotes) a set of objects (Lat. species-a species), which is identified by fixing the nearest, superordinated set (Lat. genus_-a kind) and a feature specific (differentia specifica) for the definiendum.

A real definition can play the role of an essential definition, which gives an essential, important description of defined objects [7] (p. 83). What does it, however, mean? When can a description be correctly acknowledged as an essential one? In order to analyse the topic more thoroughly, let us consider the following example: "formulating a real definition of a species of objects, i.e., a chemical element, we define it by listing a set of properties which are common to all the objects that belong to that species and which distinguish those objects from all other objects. But in doing so we do not specify all the properties that are common to all the objects in question, but only some such properties. Now it may occur that the common properties specified in a definition are selected so that, availing ourselves of the laws of nature, we can deduce from them all other important properties that are common to the objects which belong to the species under consideration. For instance, when we deduce a chemical element by describing the structure of its atoms, we specify such properties common to all samples of that element from which other important properties, such as atomic weight, valency, spectrum structure, etc., follow on the strength of the laws of nature. [...] Now if the properties that are common to various objects of a species and are specified in a definition are selected so that they not only distinguish the elements of that species from all other objects, but also are such that other important properties of the elements of that species follow from them under the laws of nature, then we say that the definition in question gives [...] an essential description of the species. Such a definition is said to describe the essence of the species it defines, and the properties specified in it are called essential. It seems that more advanced disciplines gradually tend to replace real definitions that serve merely diagnostic purposes by real definitions which describe the essence of the objects they define" [7] (pp. 83-84). Ajdukiewicz analysed the issue of a real, essential definition from a methodological and not from a metaphysical point of view. Yet, these perspectives are interconnected. The attempt to formulate a real, essential definition of a species of objects by listing a set of essential properties assumes that: (1) a species of objects has essential properties; (2) the knowledge of such properties can be obtained; and (3) such knowledge can be expressed by a definition of such a type.

The question is what essential properties are. Obviously, they are not all properties of a defined species. They are also not all common properties, but only some common ones. Thus, the question arises: which properties are those specific ones which might be listed in the definition of that species? A hypothetical answer is that the essential, specific properties are those that play a crucial role in reasoning called explanation. The assumption is that if we know, for example, the essential properties of the defined species of chemical elements $A$ and $B$, then we can deduce that they will or will not react with each other because of their chemical structure. 
However, a critic can posit a question: How can it be known for sure that such and such properties are essential ones? The answer is that the acceptance of the hypothesis concerning essential properties is practically useful in the procedure of scientific explanation and prediction of regularities (laws) of nature.

\section{Definiens as a Revisable and a Fallible Expression}

A real definition of an object is a statement giving an unambiguous description of that object. Such a definition may be true or false. It is true if it offers an unambiguous description of that object [7] (p. 81). But what is this unambiguous description (definiens)? Namely "if the description given in a real definition of a species $A$ is not a good description of the species $A$, but is a good description of a species which is superordinated to $A$, or a species which is subordinated to $A$, or a species which overlaps with $A$, or even a species which is mutually exclusive with $A$, then such a definition is a false statement. Every false definition is called inadequate. In particular, if the description given in a definition of a species $A$ is a good description of a species which is superordinated to $A$ and not of $A$, such a definition is called too broad. If a definition of a species $A$ gives a good description of a subordinated species, then it is called too narrow" [7] (pp. 82-83). Taking into consideration Ajdukiewicz's remarks, we could believe that an unambiguous (good) description of objects is an adequate one. In accordance with an adequate description, the meanings (extensions) of definiendum and definiens are equal. But is it a correct view? I will analyse this topic in the following sections.

We can say that a real definition is true if, in fact, it gives an unambiguous description of the characterised class of objects. However, the evaluation of whether a real definition is true seems to be problematic because there is no definitive criterion for finding out which definition is really true. What we can do is to acknowledge a real definition as true with a lower or higher degree of certainty, which depends on an empirical justification of a real definition. So, "human cognition is a risky enterprise in which certainty is the ideal extreme to be sought" [9] (p. 186).

Popper's fallibilism is helpful as far as the problem of truth and certainty is concerned. He claimed that "there exists no general criterion of truth. But this does not warrant the conclusion that the choice between competing theories is arbitrary. It merely means, quite simply, that we can always err in our choice - that we can always miss the truth [...] What we once thought to be well-established, or even certain, may later turn out to be not quite correct (but this means false), and in need of correction. A particularly impressive example of this is the discovery of heavy water" [10] (p. 425). Fallibilism is just an epistemological, honest standpoint according to which human statements may be subject to revision.

"Thus the belief in scientific certainty and in the authority of science is just wishful thinking: science is fallible, because science is human. But the fallibility of our knowledge [...] does not imply that the quest for truth is mistaken. On the contrary, the idea of error implies that of truth as the standard of which we may fall short. It implies that, though we may seek for truth, and though we may even find truth (as I believe we do in very many cases), we can never be quite certain that we have found it. There is always a possibility of error. [...] Criticism, it seems, is the only way we have of detecting our mistakes, and of learning from them in a systematic way" [10] (pp. 426-427).

Applying Popper's remarks on fallibilism, it can be said that definitions of natural kind terms express an actual knowledge of a characterised class of objects. However, new knowledge of a definiendum may cause a revision of a description of the objects [2] (p. 199), [11]. A real definition can be understood as a synthesis of human knowledge concerning a topic. Such knowledge grows. That is why a definition can be revised, changed and developed. The definition of light, obtained in physics, is a good example of the process of changing and developing a real definition [12] (pp. 45-46), [13], [14] (pp. 243-248), [15,16]. 


\section{A Real Definition as a Synthetic Definition}

A synthetic definition is a linguistic postulate concerning the denotation of the definiendum [7] (p. 70), [14] (pp. 44-61). The basis of every synthetic definition is a terminological convention. The convention fixes a definiendum as a linguistic expression, which has an arbitrary acoustic or graphic shape. However, the choice of a certain shape as a name of something is limited because linguistic usages-already existing-have to be respected [2] (p. 188). A terminological convention is not a statement in which something is claimed, or denied. It is a declaration of will through which something is decided. A terminological convention is not evaluated as true or false. However, a synthetic definition is a statement in the language to which this definition belongs [7] (p. 71). So, a synthetic definition can be qualified as true or false.

A synthetic definition can be understood as a stipulative definition (a meaning postulate), which is arbitrary, for example a definition of "a metre". Then such a definition is a nominal one. Let us compare the nominal, synthetic, stipulative definition of "a metre" and the definition of water:

a A metre is one ten-millionth of the distance from the equator to the North Pole (originally defined in this way in 1793) [17].

b Water is $\mathrm{H}_{2} \mathrm{O}$.

In the case of the definition of "a metre" the definiendum has a reference. In both cases the definiendum is a terminological postulate (a stipulation). It means that we could use different shapes. But the definiens in both definitions plays a different role. In the case of the definition of "a metre" the meaning of the definiens is postulated. In the case of the definition of water the meaning of the definiens (" $\mathrm{H}_{2} \mathrm{O}$ ") is empirically confirmed: water is $\mathrm{H}_{2} \mathrm{O}$ [2] (pp. 186-187). "Stipulating definitions in the objective formulation speak about facts and things, symbolized by words, and not about words themselves" [7] (p. 73). The example of a definition in the objective formulation-as Ajdukiewicz expressed it-is the definition of water: water is $\mathrm{H}_{2} \mathrm{O}$. This objective formulation is different from the following ones: "water" means " $\mathrm{H}_{2} \mathrm{O}$ " and "water" denotes $\mathrm{H}_{2} \mathrm{O}$.

Taking into consideration the fact that the extension of notions of nominal and real definitions overlap [7] (pp. 57-58, 84), a real definition can be understood also as a type of a nominal definition, namely as a synthetic definition. Such a situation was described in the story about the paleoanthropologist, in which, on the one hand, a real, ostensive definition (definiendum) refers to a newly and empirically discovered object or a class of objects, and on the other hand, a real, synthetic, stipulative definition introduces a new word (definiendum) into a language as a name of the discovered object or a class of objects. In addition, such a definition delivers an unambiguous or even essential description of the objects.

\section{A Real Definition as an Analytic Definition}

When a new word (definiendum) is introduced into a language by a real, synthetic, stipulative definition, then such a word with its meaning becomes a "usual" element of that language. The meaning of a definiens, discovered in an empirical way, is later expressed by a real, analytic definition. The definition informs in a definiens how a definiendum is actually understood by a linguistic community. Someone who does not know the meaning of such a word can learn it by means of such a definition.

Definitional statements can be contrasted with factual statements which refer to real facts or things. They are neither definitional tautologies nor their logical consequences and must be substantiated by a direct or indirect reference to empirical data [7] (p. 73). Definitional statements are understood here as nominal, analytic, arbitrary definitions (typical meaning postulates). Such definitions are opposed to real, analytic definitions, understood as descriptions of objects.

We can use a description to characterise an object. However, the name, which refers to the object, is not a synonym of the description [18] (p. 109). The definiendum and definiens of the definition of a natural kind term are not synonyms. The definiens does not deliver a statement which is unquestionably true, certain and full [2] (p. 198). The statement is only acknowledged as true with a degree of certainty. 
We do not know the laws of nature in advance in a full way. This is why we must leave open extensions of natural kind terms. Such a strategy seems to be better than an attempt to fix these extensions in a full way [6] (pp. 70-75, 199-200). "It is beyond question that scientists use terms as if the associated criteria were not necessary and sufficient conditions, but rather approximately correct characterizations of some world of theory-independent entities, and that they talk as if later theories in a mature science were, in general, better descriptions of the same entities that earlier theories referred to" [3] (p. 237).

\section{Conclusions}

A real, ostensive definition [19] fixes a reference of a definiendum. A real definition expresses also a description (definiens) of the class of objects. If such a definition tries to deliver a description of essential properties of characterised objects, then it is called a real, essential definition.

A nominal, synthetic, stipulative definition and a real, synthetic, stipulative definition are partially similar and partially different. In both cases the linguistic (acoustic or graphic) shape of definiendum is arbitrary and intentionally stipulated. We could use a different word instead of "a metre" or "water" to denote a metre or water. In both situations definiendum denotes an extension, but in the case of a nominal definition the meaning (reference) of a definiendum is fixed in an arbitrary way. In the case of a real definition the meaning (reference) of a definiendum is empirically fixed and it is not arbitrary.

The meaning of the definiens of a nominal definition is arbitrary and non-empirically stipulated. The meaning of the definiens of a real definition is not arbitrary. It is empirically discovered in, perhaps, an endless process of following revisions and corrections (a redefinition). Such a definiens expresses the meaning (sense) of a definiendum. So it seems that the "direction" of fixing a meaning (sense) is from a definiendum to a definiens.

The Ajdukiewicz's concept of a real definition-as I tried to show-is still important and it is worth developing. The paper presents a real definition as a useful method in empirical sciences. It would also be interesting to work out the theory of a real definition suitable for formal sciences: mathematics, logic and computer science. This can be a good topic for another article.

Acknowledgments: I express my gratitude to Andrzej Bronk (John Paul II Catholic University of Lublin, Poland), Agnieszka Lekka-Kowalik (John Paul II Catholic University of Lublin, Poland), Witold Marciszewski (University of Białystok, Poland), Tadeusz Szubka (University of Szczecin, Poland) and the anonymous referees for their helpful remarks.

Conflicts of Interest: The author declares no conflict of interest.

\section{References and Notes}

1. Rosen, G. Real Definition. Anal. Philos. 2015, 56, 189-209. [CrossRef]

2. Kublikowski, R. Definicje i rozwój wiedzy. Od Arystotelesa do Putnama (Definitions and the Growth of Knowledge: from Aristotle to Putnam); The Learned Society of the John Paul II Catholic University of Lublin: Lublin, Poland, 2013.

3. Putnam, H. Mind, Language, and Reality, Philosophical Papers; Cambridge University Press: Cambridge, UK, 1975; Volume 2.

4. Zinjanthropus boisei in The Smithsonian National Museum of Natural History. Available online: http: / /humanorigins.si.edu/evidence/human-fossils/fossils/oh-5 (accessed on 15 March 2016).

5. McGinn, C. The Mechanism of Reference. Synthese 1981, 49, 157-186. [CrossRef]

6. Putnam, H. Realism and Reason. Philosophical Papers; Cambridge University Press: Cambridge, UK, 1983; Volume 3.

7. Ajdukiewicz, K. Pragmatic Logic; D. Reidel Publishing Company: Dordrecht, The Netherlands, 1974.

8. Ajdukiewicz, K. On Definitions. Dialectics And Humanism 1984, 236-256. [CrossRef]

9. Marciszewski, W. Logic from a Rhetorical Point of View; Walter de Gruyter: Berlin, Germany, 1994.

10. Popper, K.R. The Open Society and its Enemies; Routledge: New York, NY, USA, 2003; Volume 2. 
11. Weingartner, P. Definitions in Russell, in The Vienna-Circle and in The Lvov-Warsaw School. In the Vienna-Circle and The Lvov-Warsaw School; Szaniawski, K., Ed.; Kluwer Academic Publishers: Dordrecht, The Netherlands, 1989; Volume 38, pp. 225-247. Weingartner's illuminating paper, treating definitions in a broad context, deserves separate and detailed studies.

12. Ajdukiewicz, K. Zarys Logiki (An Outline of Logic); Państwowe Zakłady Wydawnictw Szkolnych: Warszawa, Poland, 1958.

13. Ajdukiewicz, K. Three Concepts of Definition. Logique et Analyse 1958, 1, 114-126. [CrossRef]

14. Ajdukiewicz, K. Język i poznanie (Language and Cognition); Polish Scientific Publishers: Warszawa, Poland, 1985; Volume 1.

15. Marciszewski, W. Arguments Founded on Creative Definitions. In Empirical Logic and Public Debate. Essays in Honour of Else M. Barth; Krabbe, E.C.W., Dalitz, R.J., Smit, P.A., Eds.; Rodopi: Amsterdam, The Netherlands, 1993; pp. 169-182.

16. Marciszewski, W. Real Definitions and Creativity. In the Heritage of Kazimierz Ajdukiewicz; Sinisi, V., Woleński, J., Eds.; Rodopi: Amsterdam, The Netherlands, 1995; pp. 181-194.

17. Metre. Available online: https://en.wikipedia.org/wiki/Metre (accessed on 15 March 2016).

18. Putnam, H. Realism with a Human Face; Conant, J., Ed.; Harvard University Press: Cambridge, MA, USA, 1990.

19. Marciszewski, W. Ostensive Definition as a Prototype of a Real Definition. In Consciousness, Knowledge, and Truth. Essays in Honour of Jan Srzednicki; Poli, R., Ed.; Kluwer Academic Publishers: Dordrecht, The Netherlands, 1993; pp. 95-106.

(C) 2016 by the author; licensee MDPI, Basel, Switzerland. This article is an open access article distributed under the terms and conditions of the Creative Commons Attribution (CC-BY) license (http://creativecommons.org/licenses/by/4.0/). 